\title{
El malecu: Una cultura en peligro de extinción
}

\section{Maleku: A Culture in Danger of Extinction}

\author{
Elvia Espinoza Romero ${ }^{l}$ \\ Ministerio de Educación Pública \\ San José, Costa Rica \\ elvespro@hotmail.com \\ Noemy Mejía Marín ${ }^{2}$ \\ División de Educación Rural, Centro de Investigación y Docencia en Educación (CIDE) \\ Universidad Nacional \\ Heredia, Costa Rica \\ noemym20@gmail.com \\ Sandra Ovares Barquero 3 \\ División de Educación Rural, Centro de Investigación y Docencia en Educación (CIDE) \\ Universidad Nacional \\ Heredia, Costa Rica \\ sovares@costarricense.cr
}

Recibido 05 de mayo de 2010 • Aceptado 31 de agosto de 2010

\begin{abstract}
Resumen. El presente artículo versa sobre una de las lenguas indígenas de Costa Rica, el malecu. Esta lengua es una de las que aún se mantienen vivas en el país; no obstante, la comunidad lingüística que la practica, compuesta por menos de 400 personas, tiende a reducirse aceleradamente. Existe un alto riesgo de que en el futuro próximo dicha lengua llegue a desaparecer. El artículo surge como producto de un proyecto de investigación que se plantea la construcción e implementación deestrategias de aprendizaje,queincorporenlascostumbres, tradiciones y lengua autóctonadelosindígenas malecu; todo esto en el ámbito escolar, para fortalecer la identidad y la cultura de esta población indígena costarricense.
\end{abstract}

En un primer momento, se hace una breve reseña de la historia y las problemáticas de la población indígena malécu. Luego, se argumenta sobre la importancia de la lengua y de la oralidad. Asimismo, se hace un repaso de cómo se da en la actualidad la enseñanza de las lenguas indígenas en las escuelas costarricenses. Posteriormente se expone un diagnóstico de la situación actual de la lengua, desde la perspectiva de diferentes actores de la comunidad malécu. Este diagnostico es un insumo elaborado en la investigación, que permitirá seguidamente enfocarse en un concepto apropiado para la integración curricular rural y el currículo malécu. Finalmente se obtienen algunas reflexiones en torno a la educación intercultural bilingüe.

Palabras claves. Educación intercultural, oralidad, cosmovisión, malecu.

\footnotetext{
Máster en Administración Educativa de la Universidad Central, Costa Rica. Licenciatura en I y II ciclos con énfasis en Educación Rural. Asesora Nacional del Ministerio de Educación Pública en el énfasis de la Administración Educativa. Con varias publicaciones entre ellas: Estudios Sociales Nacho de Primero a Sexto Grado (6 tomos), Editorial Susaeta en España. Magíster en la Maestría en Formación de Formadores de Docentes de Educación Primaria.

2 Maestría en Formación de Formadores de Docentes de Educación Primaria, Universidad Nacional de Costa Rica (2010). Licenciatura en Administración Educativa, Universidad Nacional de Costa Rica (2001). Bachillerato en Ciencias de la Educación con concentración en Educación Básica I y II ciclos, Universidad Nacional de Costa Rica (1997). Ha impartido diferentes cursos para formar docentes de primaria. Ha participado en proyectos como: "Proyecto capacitación de maestros de lengua y cultura ngäbes", "Proyecto educación continua en el contexto rural", "Proyecto de Liderazgo y gestión directiva en las instituciones educativas unidocentes y dirección 1" y "Proyecto Apuja mafanh recuperando nuestra identidad" con la población. Ha participado en varias comisiones: "Comisión de trabajos finales de graduación", "Comisión interinstitucional Siwä Päko para brindar oportunidades de educación a la comunidad cabécar de Chirripó” y representante de la UNA ante la subcomisión de coordinación con pueblos indígenas, CONARE. Tiene varias publicaciones entre ellas: Historias Malecu (1994) e "Historias Malecu II (1995).

3 Máster en Administración Educativa. Ha desarrollado experiencia en currículo, biología y administración educativa. Académica de la División de Educación Rural del Centro de Investigación y Docencia en Educación (CIDE), Universidad Nacional (UNA), Costa Rica. Subdirectora de esta Unidad Académica. Magíster en la Maestría de Formación de Formadores de Docentes de Educación Primaria. Tiene publicaciones en el campo de la educación indígena.
} 


\begin{abstract}
This paper is about the Maleku, one of the indigenous languages that is still alive in the country; though the linguistic community that uses it, composed of less than 400 people, tends to reduce rapidly. There is a high risk that in the near future this language will disappear. This paper is the result of a research project that proposes the construction and implementation of learning strategies that would help to include the customs, traditions and the native language of the Malekus in the schools, to strengthen the identity and culture of this Costa Rican indigenous population.

The research project includes a brief overview of the history and problems of the indigenous Maleku population, and an analysis on the importance of the language and oral expression. It also makes a review of how the indigenous languages in Costa Rican schools are currently taught. It later includes a diagnosis of the current situation of language from the perspective of different members of the Maleku community. This diagnosis is based on the research conducted and it will facilitate focusing on the integration of the Maleku and rural curriculums. Finally, there are some reflections about the bilingual intercultural education.
\end{abstract}

Keywords. Intercultural education, world-view, oral expression, Maleku.

\title{
Generalidades de la cultura malecu
}

La población malecu, también conocidos como indios guatusos, ha enfrentado diversas situaciones a lo largo de su historia. Se ha estimado que esta población indígena antiguamente habitaba a lo largo de toda la cuenca del Río Frío, en la zona norte del país, abarcando cerca de 100 000 hectáreas (Castillo, 2005). Por mucho tiempo, estuvieron lejos del contacto con la población "blanca", incluso durante la época colonial, se mantuvieron fuera del control español, el cual se concentró, durante ese período de la historia, en la región central del país.

Con la llegada de los recolectores de hule silvestre nicaragüenses a la región en 1868, en busca del caucho y de indios para vender como esclavos en Nicaragua, empieza el replegamiento territorial de los malecu.

Para los malecu, la guerra contra los huleros significó un duro impacto, no solo territorial sino también sociocultural y humano. Como lo señalan Guevara y Chacón (1992), estas incursiones de huleros explican el brutal descenso demográfico que sufrieron. Según Arguedas (1972), el nombre del río La Muerte recuerda donde, se presume, ocurrió una de las más grandes masacres. Por su parte, Castro, Blanco y Constenla (1993) explican que la guerra con los invasores huleros llevó a los malecu casi a la extinción, hasta que a finales del siglo XIX, mediante intervención del obispo de Costa Rica, Bernardo A. Thiel, se persuadió al gobierno de enviar un destacamento militar a la región con el fin de imponer la ley y soberanía.

A raíz de lo anterior, el estado emitió un decreto que prohibía la persecución de los indios y la extracción de caucho (Decreto $\left.{ }^{\circ} 14\right)$. Sin embargo, estos eventos dejaron fuertes impactos en el pueblo malecu: los indios sobrevivientes quedaron reunidos en las tres aldeas actuales, en la parte sur de sus antiguos dominios.

Durante la primera mitad del siglo XX fueron pocos los colonos que llegaron a la región de los malecu, por lo cual el contacto con foráneos era casi nulo, con excepción de algún comercio con ellos, las visitas esporádicas de sacerdotes católicos y el estar sometidos a las leyes nacionales (Castro et al., 1993). En la segunda mitad de ese siglo, se incrementó la venida de inmigrantes de 
otras regiones del país y de Nicaragua, de tal forma que se generó, por parte de los foráneos, una nueva presión muy fuerte sobre las tierras de los indígenas. Asimismo, las instituciones del Estado irrumpieron en la región, en los años de 1960, introduciendo escuelas, misioneros religiosos y proyectos de vivienda que repercutieron en “(...) un acelerado proceso de integración y aculturación (...)” de los malecus (Guevara y Chacón, 1992, p. 103).

Con la legislación que tutela derechos territoriales de los indígenas, no se termina la usurpación y despojo de las tierras de los malecus. De acuerdo con Chacón (1988), este territorio indígena ha sido uno en los cuales se ha practicado de manera ilegal una reducción de su cabida, pues cuando se constituyó, por medio de un decreto en 1976, se estableció como superficie un área de 2994 hectáreas; pero, un año más tarde, mediante el decreto ejecutivo 7962-G de 1977, se redujo su extensión a 2743 hectáreas.

A pesar de la declaratoria de "reserva" indígena y de la Ley n ${ }^{\circ} 6172$ de 1977, en su artículo 3, que establece que: “(...) las reservas indígenas son inalienables e imprescriptibles, no transferibles y exclusivas para las comunidades indígenas que las habitan (...)" (Asamblea Legislativa de la República de Costa Rica (1977), los malecus han seguido perdiendo extensas zonas durante los últimos años. Guevara y Chacón (1992) refieren incluso actos de fuerza que protagonizaron los malecus, entre 1986 y 1990, en vista de la problemática de tierras usurpadas por no indígenas, cuando invadieron una propiedad perteneciente a un no indígena dentro de la propia reserva.

\section{Datos actuales del Territorio Indígena de Guatuso}

Actualmente, la comunidad indígena tiene una población aproximada de 460 personas, de las cuales, entre niños y adultos, 300 son hablantes distribuidos en 3 comunidades muy cercanas entre sí (Palenque El Sol, Palenque Margarita y Tonjibe) las cuales conforman el Territorio Indígena de Guatuso.

Dicho territorio abarca, en la actualidad, una extensión de 2994 hectáreas, pero como se ha dicho, existen problemas de tenencia de la tierra en manos de personas no indígenas, lo cual ha provocado que, actualmente, solo un $20 \%$ de esta superficie está en manos de los indígenas (Organización Panamericana de la Salud [(OPS], 2003).

Una característica generalizada es que en los tres palenques que conforman este territorio, aún se practican costumbres y tradiciones propias como: la caza y pesca, comidas autóctonas, sepulturas, artesanía comercial, diferentes cantos, entre otros. Sin embargo, la población joven no está hablando su idioma: algunos lo entienden, pero no lo hablan. La población ha sufrido un proceso de aculturación, producto de la imposición del idioma español y del cristianismo.

Existen historias y leyendas, así como rituales fúnebres, en los cuales se utilizan diferentes cantos que únicamente los hombres están autorizados a pronunciar o participar, práctica que en las nuevas generaciones se pierde de manera acelerada.

Es importante indicar que los malecus aún conservan el mito cosmogónico en el cual se explica la creación del mundo y de los hombres (Castro et al., 1993). Las prácticas culturales, como la caza de tortugas de agua dulce, realizadas en la región de Caño Negro y la pesca en verano, parte 
de su cultura desde épocas inmemoriales, han sido prohibidas por el Ministerio del Ambiente. Pese a ello, esta actividad se práctica hoy en forma clandestina.

\section{La pérdida de la lengua y de la identidad}

La escuela, tradicionalmente un mecanismo de aculturación, no ha contribuido a reforzar la identidad malecu; por ejemplo, los estudiantes reciben las lecciones de materias básicas en español, se les enseña la lectura y la escritura del español y cuando ya lo leen y lo escriben, se les enseña su lengua; esto, porque la norma ha sido la enseñanza del idioma oficial: el español. Si bien es cierto que en la actualidad hay políticas educativas que contemplan la revitalización del uso de las lenguas indígenas, también es cierto que hay ausencia de estrategias de aprendizaje para las lenguas autóctonas.

La población estudiantil es bastante heterogénea, existen niños y niñas indígenas y no indígenas en las tres comunidades malecus, además el nivel de dominio de la lengua es variado.

Con respecto al uso de la lengua, las familias hablan más el español en sus casas que el malécu, a excepción de la comunidad de Tonjibe, en donde la mayoría de los niños entienden y hablan el idioma vernáculo.

Según el criterio de algunos habitantes dentro de la comunidad, otra de las razones de la paulatina pérdida de la lengua indígena es el hecho de formar pareja con personas no indígenas, puesto que el (la) compañero(a) de origen foráneo no conoce la lengua y, por lo tanto, se privilegia el uso del español como medio de comunicación, a expensas del malecu.

Otro factor que influye son los diferentes niveles de conocimiento y dominio de costumbres, tradiciones, cuentos y leyendas por parte de las familias. Aunado a esto, el cambio generacional acarrea consecuencias: al ser estas culturas netamente orales, cuando mueren los ancianos muchos aprendizajes y conocimientos se olvidan.

La pérdida de la comunicación oral y de la transmisión de los conocimientos aportados por los ancianos ha provocado que ya no se practiquen o no se manifiesten muchos elementos que eran propios de la cultura y la cosmovisión malecu. Así por ejemplo, ahora hay una ausencia de la observación del mundo con los cinco sentidos, ya no se retoman los ciclos de vida de plantas y animales endémicos, ni se aplican los diversos conocimientos de etnobotánica; tampoco se utiliza la luna como astro del firmamento que, a partir de sus diferentes fases, ha orientado a las generaciones pasadas en la siembra y recolección de productos agrícolas, y guiaba en los ciclos de nacimientos de los niños y niñas. Estos elementos y manifestaciones contribuían como materia prima en la construcción de los saberes cotidianos. La ausencia de estos saberes en la escuela y en sus hogares aceleró la pérdida de identidad y pertenencia.

\section{Importancia de las lenguas y la oralidad}

En algunos países de América, las lenguas indígenas han logrado ser consideradas oficiales, tal es el caso de Paraguay con respecto al guaraní. En otros países, como Guatemala, aún se sigue discutiendo si se otorga dicha condición a sus lenguas vernáculas, a pesar de que más del 50\% de la 
población es indígena. No obstante, se puede constatar, en general, que la legislación de la mayoría de los países de la región reconoce a las poblaciones indígenas el derecho a recibir educación en su lengua ancestral. Así ocurre, por ejemplo, en Argentina, Bolivia, Brasil, Chile y México.

Pese a ello, es muy poco el avance respecto de este ideal y en el cumplimiento de la legislación. La oficialidad se traduce en el uso parcial de los idiomas indígenas en el espacio educativo formal y en algunos medios de comunicación, fundamentalmente orales. Pero se ha hecho muy poco para ir más allá del campo educativo e incorporar los idiomas indígenas en otros órdenes de la vida social.

Desde 1942, el Instituto Indigenista Interamericano promovió una propuesta educativa para las comunidades indígenas, basada en la integración y la modernización de sus economías, con el fin de facilitar su incorporación al mercado internacional y superar el regazo económico y social del campesinado indígena (Bolaños, 2002).

Si bien las democracias de América Latina conocen las realidades multiculturales, son escasos los países que enfrentan la realidad de sus sociedades ante el desafío denominado interculturalidad. No hay que limitarse a solo conocer estas realidades, sino respetarlas, fortalecerlas y promoverlas como identidades nacionales para facilitar los cambios que orienten a nuevas relaciones, a diálogos, a aperturas, a compromisos profundos para descubrir al otro. Es tarea de todos y todas entender y respetar la diversidad cultural como patrimonio y legado de todos los pueblos.

De acuerdo con Catrileo (1995), la lengua es solamente una parte de la cultura y, en el caso de las culturas indígenas, la oralidad de sus lenguas constituye su forma de uso predominante, cuyo desarrollo y diversificación hace posible cumplir funciones sociales de su cosmovisión.

Otros lenguajes y formas narrativas también florecen a la luz de las culturas de los pueblos indígenas, tales como la narrativa visual de sus artes, los lenguajes gestuales, rituales y simbólicos con que se transmite y recrea su tradición.

La oralidad en las culturas indígenas se define como fugacidad y permanencia; es la conjunción entre lo inmediato y lo mediato, entre la memoria ancestral y la no memoria. Este fenómeno doble ha permitido a la oralidad debatirse entre el mundo de la cultura escrita y transformarse. Las culturas orales existen porque tienen una historia y valores comunes, pero las culturas escritas parecieran no contar con esta fortaleza, se cree que al estar en los libros, las tradiciones no se pierden, por lo tanto, la memoria no es fugaz.

Quizá por eso se le ha dado a la escritura el estatus de materialización de la palabra. En nuestros días hay una proliferación de imágenes, de escritos y la televisión se ha convertido en el avasallador escudo de la cultura. Y la radio ha pasado a ser un medio secundario.

Según Rodríguez (2002), los pueblos orales tienen formas de recordar sucesos y reproducirlos, así la historia de las comunidades sin escritura no se pierde. Una manera de recordar hechos memorables y asociarlos con sucesos son las conversaciones que se llevan a cabo en los ambientes del campo, así, por ejemplo, es común escuchar “(...) el año del temblor (...)”, “(...) cuando vino el huracán (...)", “(...) la sequía que nos hizo perder las cosechas (...)”. La oralidad es acumulativa, conservadora, una forma de comunicación vivencial y, por lo tanto, duradera.

Estas sociedades poseen la capacidad de mantener la información por medio de la fijación de los textos orales en la memoria, textos que han sido recreados e interpretados por oradores, chamanes y diversos creadores en los discursos sociopolíticos, en rituales y en lo artístico.

El pensamiento contextualizado de las sociedades orales, al contrario de las creencias 
generales, también es teórico. Sus miembros, por medio de sus lenguas, describen los orígenes y las raíces de su existencia como grupo, con sus mitos, leyendas y tradiciones, entre otras.

Un aspecto importante dentro de cada cultura es la lengua utilizada por el grupo; la lengua, pues, está estrechamente relacionada con la forma como se interpreta la experiencia y las categorías cognoscitivas y afectivas utilizadas para conceptualizar el mundo. En este sentido, tal como lo explica Rockwell (1998), muchas culturas orales indígenas, forzadas a adoptar patrones lingüísticos y culturales diferentes, han experimentado altos niveles de estrés, una baja autoestima y una especie de desmoralización generalizada que, en muchos casos, no les permite visualizar expectativas positivas.

La oralidad es, ante todo, una forma comunicativa: ¿Cómo se puede definir la oralidad? Restrepo (1994), citando a Ong (1987), habla de oralidad primaria como “(...) la oralidad de una cultura que carece de todo conocimiento de la escritura o de la impresión. Es 'primaria' por el contraste con la 'oralidad secundaria' de la actual cultura de alta tecnología, en la cual se mantiene una nueva oralidad mediante el teléfono, la radio, la televisión y otros aparatos electrónicos que para su existencia y funcionamiento dependen de la escritura y la impresión” (...).

Esta oralidad primaria tiene una paradoja esencial: por un lado, permite que la memoria se active y admite la consulta a lo que llamaremos corpus ,que es el conjunto de conocimientos, hábitos, tradiciones, representaciones, simbolismos, significaciones y lengua en un grupo social determinado. Es decir, permite la consulta a un archivo no escrito, pero permanente. Y por otro, cuando las palabras han abandonado la boca y han sido dichas, también han dejado de existir sonoramente, aunque se abra el abanico de posibilidades hacia la significación.

En la mayoría de las comunidades indígenas, los niños y las niñas son los únicos que saben leer y escribir, en general el español, y el uso que hacen de la lectura y la escritura se limita al ámbito escolar, libros, diarios, cartas, periódicos, esto porque la literatura malecu impresa no existe. Por eso es necesario propiciar y promover la producción de sus propios textos, donde se refleje la vivencia diaria de sus historias.

¿Qué escribir, cómo escribirlo, para quién, con qué tipo de circulación, en qué formatos, con qué ilustraciones, qué gramática, alfabetos y puntuación, qué mecanismos de reproducción? Estas preguntas ilustran algunos aspectos de la cultura literaria que tienen que plantearse los escritores en lenguas indígenas.

Los abuelos y abuelas saben de su literatura a través de la oralidad. Con la enseñanza de la lecto- escritura los niños y las niñas son los llamados a alfabetizar en su propia lengua a los adultos. Así, es factible la transcripción de los textos orales.

Los niños y las niñas pondrán su pensamiento en su lengua escrita, si desde sus primeras etapas aprenden a escribir sus costumbres y otros aspectos de su cultura, es decir, su cosmovisión.

\section{Las lenguas indígenas de Costa Rica}

En Costa Rica existen 8 culturas o pueblos indígenas: bribris, bruncas, cabécares, chorotegas, guaymíes, huetares, malecus y térrabas, distribuidos en 24 territorios legalmente constituidos. Según el censo del año 2000, la población indígena del país era de 63800 personas, que representan solo el 1,7\% de la población del país. Además, se reconoce oficialmente la existencia de 6 lenguas indígenas, aunque en realidad se puede hablar de 8 , porque en los territorios indígenas guaymíes se practican dos lenguas distintas (el ngäbére en la mayor parte de los territorios, y el burglére 
entre unos pocos hablantes). Las 6 lenguas indígenas, cuya existencia es reconocida, son: el bribri, el cabécar, el guaimí (ngäbére), el malecu o lengua guatusa, el brunca y el térraba. Las dos últimas están en proceso de extinción y entre las restantes hay diversos niveles de mantenimiento, que varían de una comunidad a otra, e incluso, entre las familias de una misma comunidad.

Por esta razón, los niños indígenas ingresan a la escuela con diferentes niveles de conocimiento y uso de su lengua autóctona y del español: un 50\% es monolingüe en la lengua indígena, no habla español o no lo hace de manera funcional; un $40 \%$ son monolingüe en español, es decir, no habla ninguna lengua indígena y un $10 \%$ posee un bilingüismo coordinado, es decir, se comunica fluidamente con igual eficiencia y eficacia en ambas lenguas (Ovares y Rojas, 2008).

\section{Enseñanza de las lenguas indígenas en las escuelas de Costa Rica}

En atención a los diferentes congresos internacionales de educación intercultural bilingüe, nace, en 1990, la iniciativa, por parte de la Escuela de Filosofía de la Universidad de Costa Rica, de formular un proyecto de enseñanza de la lengua Boruca en la Escuela Doris Stone. El éxito y la acogida por parte de esta comunidad le permitió al Ministerio de Educación en 1995, incorporar otros territorios con la finalidad de revitalizar y difundir las lenguas indígenas del país, así como rescatar la transmisión oral desde su cosmovisión.

En 1997, mediante la Resolución 34-97, el Consejo Superior de Educación establece como parte del plan de estudios para escuelas indígenas, dos asignaturas: lengua indígena, con tres lecciones semanales y cultura indígena, con dos lecciones por semana (Ovares y Rojas, 2008).

\section{Docentes que atienden la cultura y la lengua}

A nivel nacional existe un grupo de maestros y maestras de lengua y cultura, cuyo nivel educativo va desde primaria y secundaria incompleta, no se cuenta con ningún maestro de estos que tenga formación universitaria. Por tal razón, los salarios que se pagan responden a la categoría de aspirante; este salario es simbólico, además implica poca posibilidad de ascenso y de nombramientos a largo plazo.

En la mayoría de los casos, el conocimiento pedagógico que poseen estas personas es el que su experiencia de vida les ha permitido construir, tanto en la cultura como en su lengua; es decir, una cultura e idioma heredados desde la oralidad.

Un importante porcentaje de maestros de lengua y cultura son varones, situación que responde a la necesidad de desplazarse por caminos inseguros y en zonas geográficas de difícil acceso, las lecciones que imparten son de manera itinerante en escuelas ubicadas lejos una de la otra. Además, se parte del supuesto de que, para una mujer, realizar esta labor sería más complicado.

La condición laboral de itinerancia obliga a atender varias escuelas en una semana, esta situación genera falta de pertenencia e identidad con la comunidad y la escuela; contribuye, también, a no desarrollar arraigo, así como mayores niveles de compromiso.

El trabajo que comparten en los centros educativos en muchas ocasiones es desvalorizado y no complementado con las temáticas que desarrolla el docente que imparte Ciencias, Matemáticas, entre otras disciplinas.

Como la enseñanza de lengua y cultura no es una asignatura que reporta una nota para 
su aprobación, los padres y madres de familia no le dan importancia, por lo que los maestros y maestras de lengua y cultura deben mantener una constante incentivación en los niños y niñas, con el fin de que estos valoren su cultura.

En estos procesos, se da un choque metodológico: los niños y niñas quieren aprender utilizando el entorno escolar, de acuerdo con su cultura y visión de mundo. El docente que imparte conocimientos de las asignaturas básicas, lo hace por separado y dentro de cuatro paredes, la pregunta es: ¿existe relación entre el aprendizaje que desarrolla el maestro y maestra de las asignaturas básicas y el de lengua y cultura? La respuesta: muy poca.

Una política emanada por el Ministerio de Educación Pública es que, en las escuelas de enseñanza primaria de las comunidades indígenas, se desarrolle un programa de enseñanza en su propia lengua y prácticas cotidianas que contribuyan a revitalizar las diferentes culturas. Siguiendo esta directriz, los objetivos de los cursos de lenguas indígenas y, por lo tanto, de sus maestros, son los siguientes:

"1.Revitalizar y difundir las lenguas indígenas del país mediante su enseñanza a niños y jóvenes.

2. Desarrollar en los estudiantes habilidades de expresión oral y escrita en la lengua indígena.

3. Promover el aprecio por la literatura tradicional indígena.

4. Dinamizar procesos de educación bilingüe.

5. Facilitar el proceso de transición de la lengua indígena al español.

Los objetivos referidos a la lengua los complementan los cursos de cultura indígena (...):

1. Promover el fortalecimiento de las culturas indígenas mediante la enseñanza de elementos fundamentales de su cultura: historia, filosofía, organización sociopolítica, economía y relación con la naturaleza.

2. Fortalecer la identidad étnica y cultural indígena, mediante el conocimiento y valoración de las prácticas ancestrales, valores, destrezas, habilidades y saberes autóctonos.

De este programa se desarrollan las siguientes actividades:

- Enseñanza de las lenguas indígenas a los niños y jóvenes de las instituciones educativas indígenas, sea como lengua materna o como segunda lengua. Los educandos reciben tres lecciones semanales de la lengua indígena y las dos lecciones de cultura, las cuales, en la mayoría de los casos, se desarrollan en la lengua indígena correspondiente.

- Elaboración de programas de estudio para los cursos de lengua y cultura indígena. Estos programas se revisan periódicamente.

- Capacitación integral y constante a los docentes de lenguas y culturas indígenas.

- Elaboración de material didáctico apropiado para el desarrollo de los programas de los cursos.

- Creación de un marco legal y laboral adecuado para que los docentes de lengua y cultura desarrollen sus funciones". (Ovares y Rojas, 2008, pp. 13-14)

En este marco, es importante el diseño de materiales propios de su cultura y echar mano de 
los cuentos, las historias - como es el caso de la creación de la tierra, entre otras-, las leyendas, los cantos fúnebres, los de siembra o los relacionados con el nacimiento de un miembro en la familia. Es aquí donde el conocimiento de los ancianos y de los maestros y maestras de lengua y cultura se vuelve importante: La sabiduría ha de pasar de generación en generación.

\section{Hallazgos que dan fundamento}

Con el fin de explorar acerca de la problemática de la comunidad indígena malecu, se ha propuesto construir espacios de reflexión para la valoración de su lengua y cultura autóctona. De esta forma, se trabajó con niños, jóvenes, docentes y adultos de los tres palenques indígenas malecus.

Para recopilar la información, se procedió a la aplicación de un cuestionario que consta de preguntas abiertas y cerradas, de una entrevista a profundidad a informantes claves. Estos grupos de informantes serán identificados con las letras G1, G2 y G3 para efectos de no repetir la categoría de informantes y resguardar su anonimato.

El análisis de las información se llevó a cabo en tres bloques: de jóvenes (G1), constituido por un total 10 estudiantes; adultos (G2), conformado por 6 personas y (G3) compuesto por 6 docentes, 4 regulares y 2 de lengua y cultura. Para efecto de análisis, el G3 se subdivide en (G3a) los docentes de lengua y cultura, y (G3b) los docentes regulares. Los datos aportados por los participantes de los tres grupos, en términos de pérdida de lengua y cultura, se analizan por categorías derivadas de cada bloque, las que se respaldan con expresiones textuales de los participantes.

El primer grupo correspondiente a G1 se analiza a partir de seis categorías:

\section{Estudiantes y jóvenes}

\begin{tabular}{ll}
\hline Categorías & Descripción de la información \\
\hline - Habla la lengua malecu. & Los jóvenes de la comunidad malecu, en un porcentaje significativo, no \\
\hline - Escribe la lengua malecu. & $\begin{array}{l}\text { hablan su lengua materna y si lo hacen es de manera ocasional. } \\
\text { Los jóvenes de la comunidad malecu, en un porcentaje significativo, } \\
\text { manifiestan que, de manera ocasional, escriben el malecu. }\end{array}$ \\
$\begin{array}{ll}\text { Papel de la escuela en la revitalización de } \\
\text { la lengua y la cultura. }\end{array}$ & $\begin{array}{l}\text { La escuela no es un ente que contribuye a revitalizar la lengua y la cultura, } \\
\text { porque los docentes, en su mayoría, desconocen la cosmovisión malecu, a } \\
\text { excepción de los docentes de lengua y cultura que conocen un poco más. }\end{array}$ \\
$\begin{array}{l}\text { Materiales didácticos de apoyo a la lengua } \\
\text { y la cultura. }\end{array}$ & $\begin{array}{l}\text { En su totalidad, manifiestan una ausencia de textos como material didáctico } \\
\text { pertinente, con respecto a la enseñanza de la lengua y la cultura malecu. }\end{array}$ \\
de la lengua y la cultura. & $\begin{array}{l}\text { Manifiestan, en un porcentaje significativo, que la comunidad no ha } \\
\text { contribuido a la revitalizar la lengua y cultura, porque los miembros de la } \\
\text { población se han cruzado con otras culturas. }\end{array}$
\end{tabular}

En términos generales, en el cuadro anterior se confirma una ausencia en el dominio tanto de la escritura como de la lengua en las nuevas generaciones, así como la ausencia de materiales didácticos propios. Uno de los estudiantes manifestó “(...) que en la escuela ha diseñado jícaras, bolsos y diferentes dibujos que ilustran la cultura (...)”; no obstante, el impulso a la creación y producción de materiales debe ser constante, como una forma de mantener y recuperar su cultura.

En cuanto al papel de la escuela, hay quienes afirmaron que también propicia el rescate de 


\section{URL: http://www.una.ac.cr/educare}

las leyendas, historias, artesanías y otros, de manera que contribuye con la identidad y la cultura de este grupo indígena.

Es necesario recordar que las lecciones de lengua y cultura en el ámbito escolar ocupan un pequeño espacio dentro del calendario semanal. En ese sentido, el aprendizaje de la lengua indígena es limitado, frente al proceso de lectoescritura del español que se desarrolla desde los primeros años escolares.

Estructuralmente, el modelo educativo privilegia la enseñanza de una lengua en detrimento de la otra, por lo cual la escuela se revela como una de las principales razones que explican el escaso dominio de la lengua malecu, presente entre las nuevas generaciones.

El reducido manejo de esta lengua entre los jóvenes permite inferir que cada vez hay menos contextos sociales en los cuales la lengua es utilizada, y, por lo tanto, va perdiendo terreno frente al español.

A continuación, el análisis del segundo grupo, correspondiente a G2, se realiza a partir de diez categorías:

Adultos

Categorías Descripción de la información

- La función de la escuela en la revitalización de la lengua y la cultura.

En su mayoría consideran que la escuela no está cumpliendo esa función en su totalidad.

- Actividades que realiza la comunidad para mantener viva la lengua y la cultura.

Consideran, en su mayoría, que existen algunos grupos de teatro, los cuales fueron creados con fines de atracción turística, no con fines de rescate cultural.

- Hablar la lengua malecu genera discriminación por parte de los no hablantes.

Consideran que la lengua malecu la deberían hablar todos los integrantes de esta comunidad, porque esto no es un factor que discrimina.

- Uso cotidiano de la lengua malecu en el entorno familiar.

- Interés de los padres de familia para que sus hijos aprendan a hablar malecu.

- Enseñanza de la lengua malecu, costumbres y tradiciones tanto en la casa como en la escuela.

- Responsables de mantener la lengua, costumbres y tradiciones.

Consideran, en su gran mayoría, que entre las personas mayores la lengua malecu sí se habla, no así en las generaciones jóvenes.

En un alto porcentaje, consideran que las nuevas generaciones deberían aprender y tener dominio de la lengua.

Consideran, en un alto grado, que tanto la escuela, como los integrantes de las familias, deben transmitir las costumbres y tradiciones.

La gran mayoría contestó que la responsabilidad de mantener la cultura y la lengua está en la familia, pero recae también en los maestros.

- Interés por parte de los adultos de participar en proyectos de revitalización de costumbres y tradiciones malecus.

- Necesidad de documentar costumbres y tradiciones autóctonas.

Todos los entrevistados manifiestan su interés por participar en proyectos de revitalización de costumbres y tradiciones malecu.

Todos manifiestan su interés en documentar costumbres y tradiciones autóctonas.

- Prácticas artesanales elaboradas en la escuela.

En su mayoría, consideran que en la escuela realizan diferentes tipos de artesanías.

Los adultos consideran que comunicarse en su propia lengua permite mantener viva las 
historias ancestrales. Esta afirmación se respaldan con el siguiente aporte de los adultos: “(...) algunos se enojan por no entender y piensan que uno está hablando de ellos, a otros les gusta que se les enseñe la lengua (...)”; “(...) algunos jóvenes no lo hablan por vergüenza, y porque los discriminan (...)". "De continuar así, esta lengua estaría en peligro de desaparecer".

Para los adultos, los principales responsables de mantener viva la lengua son la familia y después la escuela, por medio de los maestros de lengua y cultura, según lo plantea uno de los adultos: “(...) hablándole y narrando las historias malecus, enseñándoles a los hijos mediante la práctica, dedicándole más tiempo a la importancia de la cultura”.

Otro aporte significativo por parte del grupo de adultos es la necesidad de documentar las historias, la cultura y la lengua. Se sugiere realizar este proceso mediante un proyecto con alguna entidad que apoye con el financiamiento. Al respecto, los adultos manifiestan que “(...) esto permitiría rescatar toda la historia, tradición y lengua malecu, especialmente porque los ancianos son los que tienen la sabiduría”.

El tercer grupo correspondiente a G3a y G3b se analiza a partir de seis categorías:

Maestros y maestras de lengua y cultura (G3a) Docentes regular( materias básicas ) (G3b)

\begin{tabular}{cll}
\hline & Maestros y maestras de lengua y cultura (G3a) & Docentes regular( materias básicas ) (G3b) \\
\hline Categoría & Descripción de la información & Descripción de la información \\
\hline Pérdida de la identidad & Manifiestan, en un porcentaje significativo, & En su mayoría, coinciden con los de lengua y \\
\hline y la lengua. & $\begin{array}{l}\text { que en la comunidad malecu se ha perdido la } \\
\text { identidad y la lengua. }\end{array}$ & $\begin{array}{l}\text { cultura en que en la actualidad se está dando } \\
\text { una pérdida de la identidad y la lengua. }\end{array}$
\end{tabular}

- El diseño curricular que se imparte en la comunidad educativa malecu.

- La función de la escuela en la revitalización de la lengua y cultura a través de los docentes que imparten esa asignatura

- Actividades que realiza la comunidad para mantener viva la lengua y la cultura

- Actividades curriculares que realiza en conjunto con el maestro de lengua y cultura.

- Conocimiento del idioma y la cosmovisión del maestro de lengua y cultura.
En su mayoría, contestan que no existe un programa que responda a las necesidades y expectativas de los integrantes de esta comunidad.

En un gran porcentaje manifiestan que los maestros de lengua y cultura aportan para mantener el idioma y las tradiciones culturales.

La mayoría opina que la comunidad no realiza actividades que permitan mantener viva la lengua y la cultura.

Manifiestan que no se dan actividades curriculares conjuntas con el maestro regular que imparte las asignaturas básicas, pues cada uno desarrolla temáticas curriculares específicas.

En un alto porcentaje son conocedores de la lengua y la cultura, pero se nota una ausencia de producción de material didáctico que revitalice la cosmovisión malecu.
En su mayoría, manifiestan que existe un plan de estudios específico para las asignaturas básicas, no así para las asignaturas de lengua y cultura.

En su gran mayoría opinan que la escuela no ha dado aportes significativos a la revitalización de la lengua y cultura, porque no todos los maestros de las asignaturas básicas dominan la cosmovisión malecu.

En un alto porcentaje, coinciden tanto los maestros de las asignaturas básicas, como los de lengua y cultura que la comunidad, en su mayoría, no realiza actividades que permitan mantener viva la lengua y la cultura.

En un alto porcentaje

hacen referencia a que las únicas actividades que comparten, de manera conjunta, son las que se diseñan en el plan institucional anual. En esto se nota la ausencia de integración curricular.

En su totalidad manifiestan que el maestro de lengua y cultura conoce la cosmovisión malecu.

Algunos docentes explican que entre los programas de las asignaturas básicas y los 
lineamientos dados para la enseñanza de la lengua y cultura existe poca relación, porque no se han planteado políticas curriculares que establezcan espacios de integración curricular. En este sentido, un maestro de las asignaturas básicas manifiesta que "(...) el MEP nombra a los maestros y maestras de lengua y cultura y después se olvida de darles seguimiento y capacitación, además los docentes de lengua y cultura manifiestan la necesidad de nombrar un asesor conocedor de la cultura malecu".

También se nota la ausencia de comunicación y trabajo en equipo entre los maestros de asignaturas básicas y los de lengua y cultura. Las únicas actividades que trabajan de manera conjunta son las establecidas en el calendario escolar o plan institucional, por ejemplo: bandera azul, encuentro de culturas y demás efemérides.

En cuanto al planeamiento curricular, cuando desarrollan temáticas, los maestros regulares no toman en cuenta a los docentes de lengua y cultura, por considerarlas diferentes o sin puntos en común.

Es necesario contextualizar el currículo de la escuela indígena malecu, para que este aporte elementos a la cultura local creada y recreada de generación en generación, trasmitida de manera oral por los libros vivientes como son los ancianos, quienes guardan los saberes del pueblo y le van dando sello a la cultura, manteniendo viva la identidad y la cosmovisión propia de estos grupos.

Cuando se habla de cultura, se hace referencia a una cosmovisión, un conjunto de bienes, valores, principios, creencias, conocimientos materiales, que se relacionan y se sostienen mutuamente. $\mathrm{Al}$ intervenir en una cultura, hay que tener en cuenta que existen elementos de esa cultura que son más estables y relevantes, por lo tanto, el trabajo debe ser respetuoso, para no generar cambios que desemboquen en la modificación de patrones que lleven a la destrucción de esa cultura.

En los currículos latinoamericanos es evidente la ausencia de investigación permanente en su diseño, aplicación y evaluación. Las escuelas indígenas y rurales costarricenses urgen de un buen currículo que pretenda una educación culturalmente pertinente y, por ende, una escuela en estrecha relación con la comunidad, donde el diseño de proyectos y actividades respondan a las necesidades detectadas en los diagnósticos.

Para lograr la pertinencia curricular, eje de la educación, se debe contextualizar el currículo y desarrollar contenidos de manera integral. Particularmente en las comunidades indígenas, los niños y las niñas han de relacionarse con los fenómenos de la naturaleza y con los procesos de siembra y curación de las semillas, los movimientos de la luna, así como, la rotación de cultivos para fijar el nitrógeno de manera natural sin emplear químicos.

¿Se integran estos aprendizajes en nuestros currículos? Por ejemplo, en otras culturas indígenas, los mayores comentan que por décadas han observado que si los pájaros colocan sus nidos en las copas altas de los árboles, el tiempo será favorable, pero si sus nidos están sujetos a las ramas centrales, el invierno será violento. Un buen observador tomará sus previsiones para la siembra y el cuido de los animales. Estos son aprendizajes para la vida, por lo tanto, contenidos integrales que involucran una educación de calidad que le da respuesta a sus necesidades cotidianas.

Los ciclos de las plantas, así como las migraciones de las aves y las posiciones de las estrellas en el firmamento, son libros que nuestros antepasados han leído para sobrevivir a situaciones producidas por los cambios de la naturaleza ¿Están estos conceptos o experiencias escritos en los libros?

El trabajo realizado por diversos sociólogos, antropólogos y pedagogos interesados en el tema, o la revisión de los hechos en la División de Educación Rural confirman que, muchas veces, estos conceptos no se aplican en el currículo de las poblaciones indígenas. En consecuencia, el resultado 
para estudiantes, padres y madres de familia es el desencanto por un estudio que les resulta ajeno a su medio y a sus necesidades.

En este sentido, las poblaciones rural e indígena se enfrentan la inflexibilidad del calendario escolar, el cual, a su vez, se condiciona por la rigidez mental de quienes orientan la política educativa nacional. A pesar de los resultados positivos que ofrece la propuesta educativa desarrollada en países como Colombia, conocida con el nombre de "escuela nueva", donde se plantea una flexibilidad del calendario escolar de acuerdo con las actividades económicas de la región, en Costa Rica se continúa al margen de esta condición. En el país, las autoridades aún no comprenden que la realidad económica-social no corresponde con la lógica organizacional del sistema educativo. Esto obliga a que una gran cantidad de niños y niñas abandonen sus estudios en tiempos de cosecha y recolección de fruta, sin que se les presenten alternativas educativas al respecto.

La realidad del mundo rural e indígena necesita un currículo y una escuela diferente. La integración curricular es una opción pedagógica que permitiría en escuelas indígenas y rurales:

- Entender que la realidad como estrategia cognitiva es percibida por los niños y las niñas, sobre todo los más pequeños, como un todo y en forma global. Esta percepción sincrética servirá de punto de partida para incentivar el aprendizaje y desarrollar capacidades analíticas que luego permitirán favorecerán procesos de síntesis.

- Capacitar a las personas para resolver los problemas que enfrente, desde diferentes visiones y áreas del conocimiento y no únicamente desde una disciplina. Buscar soluciones a problemas reales y desde una perspectiva interdisciplinaria.

- Organizar el currículo de forma que despierte el interés y la curiosidad de las niñas y niños, mediante la promoción de aprendizajes que se relacionen con su entorno natural y social y que resulten prácticos para resolver los problemas surgidos en su ambiente.

- Promover los valores, formas de pensar e intereses presentes en la cultura cotidiana de las comunidades indígenas y rurales.

Es importante destacar que la integración curricular es una alternativa válida para desarrollar procesos de adecuación curricular en las escuelas indígenas. Se pretende que los niños y niñas no solo aprendan contenidos aislados, sino que también aprendan a pensar, a buscar solución a los problemas cotidianos; a desarrollar habilidades que les faciliten la interacción y comprensión de los demás y de su entorno social, cultural, económico y político, para mejorarlo.

En síntesis, la integración curricular será la forma de organizar el currículo de manera que se integren los aspectos curriculares que contempla el programa escolar oficial, con la realidad local, y con el contexto natural y social del alumno.

Esta integración curricular ha de acompañarse de estrategias metodológicas participativas que consisten en modificar la práctica educativa, para que pueda constituirse en una práctica no reproductora, sino creadora Debe plantearse como objetivo dotar a los participantes, de instrumentos o herramientas para convertirse en productores de conocimientos. Es importante observar que “(...) los mejores recursos están ahí, en nuestras leyendas y tradiciones, en los árboles, las flores y los frutos que están a nuestro alrededor y a nuestro alcance (...) (Peralta, 2008, p. 136), es así como la integración y la contextualización favorecen el valor de pertinencia.

Por esa razón, implica un trabajo de reconocimiento, de descubrimiento de nuestra 
propia práctica. Es una seria labor de investigación constante, que funde las bases del ejercicio de trasformación de la práctica educativa que se ejerce. El papel del docente será propiciar el conocimiento de la realidad; el alumno deberá desarrollar la capacidad de producción de conocimiento y sus propios medios de producción intelectuales, científico-críticos y de expresión.

La educación integral holística y armónica permite a los niños y niñas indígenas un aprendizaje para la vida en convivencia social, así como una lectura permanente del entorno natural; todo lo cual les proporciona los elementos para el aprendizaje: la utilización de diferentes plantas para la extracción de tintes; el empleo de los diferentes órganos de estas (raíces, tallos, flores, hojas) para efectos medicinales. Esto ha de utilizarse con mucho respeto: se le pide permiso a la naturaleza, para mantener el equilibrio ecológico.

\section{Reflexiones finales}

Los programas de preparación de maestros y maestras de las asignaturas básicas deben incluir, necesariamente, cursos sobre los contenidos culturales de los grupos humanos involucrados en el proceso educativo, estudios de lingüística y literatura comparada, metodologías de enseñanza de la lengua materna y enseñanza de una segunda lengua.

Además, es necesario incorporar conocimientos teóricos y prácticos sobre antropología cultural aplicada a la educación, de tal forma que los maestros y maestras de lengua y cultura, de manera conjunta con los ancianos y otros integrantes de la comunidad, puedan decidir sobre los temas que deben incorporar al currículo y la metodología apropiada para enseñarlos.

Los materiales didácticos y los recursos visuales y audiovisuales que se utilizarán para cumplir esta tarea merecen también una atención especial. Independientemente de la diversidad de nuevos enfoques y medios de enseñanza utilizados en otros lugares, los materiales didácticos deben ser apropiados para la edad, características de los estudiantes y su tipo de manejo lingüístico en el aula.

Una vez que se entienda la relación que existe entre el pensamiento, la cultura y la lengua oral o escrita, así como también las diferencias culturales, se habrán sentado las bases para que cada educador pueda incluir los aspectos de la cultura de sus estudiantes en el currículo escolar. A través de los años, algunos docentes han desarrollado procesos, por ensayo y error, en un esfuerzo por encontrar los medios más efectivos para lograr que los estudiantes se familiaricen y respeten las culturas orales indígenas.

Con la adquisición de nuevas técnicas y metodologías de estudio que consideren la diversidad cultural oral y escrita en el currículo escolar, se estará beneficiando la sociedad costarricense, en el sentido de prepararla para una vida más armónica dentro de un contexto multicultural.

Sin embargo, la educación intercultural tampoco debe convertirse en un sistema paternalista o en una especie de labor de indulgencia para los grupos indígenas. Aunque estos fueron capaces de adaptarse perfectamente a la sociedad mayoritaria en los tiempos pasados, después de la conquista, ahora necesitan desarrollar múltiples habilidades para manejar nuevos códigos y símbolos con el fin de funcionar mejor en su propio medio, y con la idea, también, de que toda la sociedad recupere parte de su patrimonio cultural perdido.

\section{Referencias bibliográficas}


Arguedas, U. (1972). Algunas notas acerca de los guatusos. [Material sobre los guatusos mimeografiado]. San José, Costa Rica: Departamento de Ciencias del Hombre: Universidad de Costa Rica.

Asamblea Legislativa. República de Costa Rica. (1977). Ley indígena $N^{\circ} 6172$ (Artículo 3). San José: Costa Rica. Autor. Recuperado de http://www.iidh.ed.cr/comunidades/diversidades/docs/ div infinteresante/ley\%20indigena\%20costa\%20rica1977.htm

Bolaños, M. (noviembre, 2002). Ruralidad y multiculturalidad en la Centroamérica contemporánea. III Seminario Latinoamericano de Educación Rural: Encuentro de Experiencias. Congreso llevado a cabo en la Universidad Nacional. Heredia, Costa Rica.

Castillo, R. (2005). El territorio histórico maleku de Costa Rica. Reflexiones, 84(1), 71-85.

Catrileo, M. (noviembre, 1995). La determinación en mapudungun. XI Seminario Nacional de Investigación y Enseñanza de la Lingüística. Congreso llevado a cabo en la Universidad Bio Bio. Chillán, Chile.

Castro, E., Blanco, A. y Constenla, A. (1993). Laca majifijica. La transformación de la tierra (Trad. y Ed. A. Constenla). San José, Costa Rica: EUCR.

Chacón, R. (1988). La tutela de los derechos indígenas en Costa Rica. Enunciación de los decretos ejecutivos que los regulan. San José, Costa Rica: Imprenta Nacional.

Guevara, M. y Chacón, R. (1992). Territorios indios en Costa Rica: Orígenes, situación actual y perspectivas. San José, Costa Rica: García Hermanos.

Organización Panamericana de la Salud [OPS]. (2003) Desarrollo y salud de los pueblos indígenas de Costa Rica. San José, Costa Rica: Organización Panamericana de Salud y Ministerio de Salud.

Ovares, S. y Rojas, C. (2008). La enseñanza de las lenguas indígenas en Costa Rica. Letras, 43, $11-21$.

Peralta, M. V. (2008). En la educación nos jugamos el futuro: ¿Qué cultura estamos legitimando en nuestras aulas? Revista centroamericana de educación, 3(1), 127-142.

Restrepo, G. (1994, septiembre). Narración, escritura e imaginarios. Nómadas, 1, 1-12. Recuperado de http://redalyc.uaemex.mx/redalyc/pdf/1051/105115239006.pdf

Rockwell, E. (1998). La dinámica cultural en la escuela (Cap. 1). En A. Álvares (ed.). Hacia un 
URL: http://www.una.ac.cr/educare

curriculum cultural. La vigencia de Vygotski en la educación (pp. 21-38). Madrid, España: Fundación Infancia y Aprendizaje.

Rodríguez, J. M. (2002, junio). Patrones y principios en la moralización de las acciones. Una investigación en la cultura bribri. Revista de Ciencias sociales, 2(96), 23-24. 